\title{
Interfaces de gênero e empoderamento da mulher no Corfebol: uma revisão descritiva*
}

\author{
Renata Laudares Silva** \\ Gisele Maria Schwartz***
}

\section{Resumo}

Baseado na perspectiva de igualdade de gênero no esporte, o estudo investigou a produção de conhecimento sobre as interfaces de gênero e empoderamento da mulher no Corfebol. Os resultados indicam a predominância de estudos sobre igualdade de gênero no âmbito dos esportes de alto rendimento, assim como no contexto das aulas de Educação Física. Porém, não há artigos diretamente relacionados às interfaces de gênero $e$ empoderamento da mulher no Corfebol na literatura acadêmica. Conclui-se que há uma premência na produção de conhecimentos considerando a temática, para minimizar esta lacuna.

Palavras-chave: Igualdade de Gênero, Empoderamento, Esporte, Corfebol.

* Recebido em 07 de dezembro de 2018, aceito em 17 de janeiro de 2020.

** Doutoranda em Desenvolvimento Humano e Tecnologias, Mestre em Ciências da Motricidade e Bacharel em Educação Física pela Universidade Estadual Paulista Júlio de Mesquita Filho, Unesp, Rio Claro, São Paulo, Brasil e pesquisadora do Laboratório de Estudos do Lazer, Departamento de Educação Física, Unesp, Rio Claro, SP, Brasil.renata.laudares@gmail.com /0000-00020200-799X

*** Professora Adjunta aposentada na Universidade Estadual Paulista Júlio de Mesquita Filho, Unesp, Rio Claro, São Paulo, Brasil e pesquisadora do Laboratório de Estudos do Lazer, Departamento de Educação Física, Unesp, Rio Claro, SP, Brasil. gisele.schwartz@.unesp.br / 0000-0003-1599-5314 

da mulher no Corfebol: uma revisão descritiva

Gender Interfaces and Women's Empowerment in Korfball: A Descriptive Review

\begin{abstract}
Based on the perspective of gender equality in sport, this study investigated the production of knowledge about gender interfaces and women's empowerment in Korfball. The results indicate the predominance of studies about gender equality in highperformance sports, and in physical education classes. However, no articles were found directly related to gender interfaces and women's empowerment in Korfball. It is concluded that there is an urgent need for production of knowledge about this theme, to minimize this gap.
\end{abstract}

Keywords: Gender Identity, Power (Psychology), Sport, Korfball. 


\section{Introdução}

O esporte é considerado uma ferramenta catalisadora de mudanças atitudinais positivas para o público feminino, graças à possibilidade de promover a melhoria da autoestima, da confiança, da autossuperação e da autonomia, elementos importantes, os quais contribuem efetivamente para o empoderamento da mulher (Lim; Dixon, 2018). Entretanto, esses efeitos podem variar, ou mesmo não serem positivos, dependendo do tipo de prática corporal, induzindo ou reforçando elementos contrários como a submissão ou a impotência feminina (Schulenkorf; Sherry; Rowe, 2016).

Com uma perspectiva igualitária, o Corfebol desde sua origem, preconizou a participação de ambos os gêneros. Essa modalidade esportiva traduz uma realidade diferenciada de outras práticas, pois traz em sua regra principal, a inclusão feminina junto à masculina, ou seja, os times são formados por homens $e$ mulheres os quais desfrutam juntos da experiência de praticarem a mesma modalidade (International Korfball Federation, 2011). Este esporte é regido por alguns princípios como a cooperação, a não violência, jogo misto, alternância de funções, habilidades técnicas e a coeducação. Pelo fato de a marcação dos atletas durante as jogadas ser feita por gênero, isto é, homens marcam homens e mulheres marcam mulheres, as vantagens esportivas tradicionais como força, altura, velocidade entre outras são enfraquecidas, havendo mais equilíbrio nas performances (Dossier de Korfbal, 2018; Gubby; Wellard, 2016).

Estes elementos são encontrados apenas no Corfebol $e$ fomentam o encorajamento para romper com estereótipos de segregação da mulher no campo esportivo, assim como, tendem a contribuir para uma possível mudança de conceito em relação à presença dos gêneros, feminino e masculino, em equipes esportivas (Gubby, 2015; Gubby; Wellard, 2016), incitando o empoderamento feminino. As ações contra as desigualdades entre gêneros no esporte, mais fortemente elencadas no passado porém, ainda presentes de diversas maneiras, tiveram que passar por um 
processo de reflexão profunda, surgindo inclusive novas perspectivas de abordagem no contexto esportivo (Singh; Naidoo, 2017).

Ao visar atuar nesta perspectiva de inclusão, equidade de gênero e empoderamento da mulher nas práticas esportivas e nas atividades físicas, o Comitê Olímpico Internacional (COI), por meio de ações e projetos que estão presentes na Agenda 2020, promove $e$ incentiva a igualdade de gênero nos diversos esportes, inclusive, em cargos de gestão esportiva ou com a inclusão de provas com equipes mistas, assim como, com cobranças junto às federações internacionais no cumprimento dessas recomendações (Lapchick, 2016).

A ONU-Mulheres, aliada a uma Organização Não Governamental denominada ONG Women Win, criada para desenvolver o empoderamento de mulheres por intermédio do esporte em parceria com o Comitê Olímpico Internacional (COI) $e$ com o Comitê Olímpico Brasileiro (COB), lançaram o programa Uma Vitória Leva à Outra. Esse Programa visa à promoção da igualdade de gênero, empoderamento e liderança para mulheres por meio das práticas esportivas e foi lançado no Rio de Janeiro, em outubro de 2015. Atualmente, integrou-se à ONU-Mulheres, o Fundo ELAS e a implementadora EMPODERA, fomentando ações multiplicadoras e impulsionadoras do empoderamento de meninas por meio do esporte (Onu-Mulheres, 2019).

Ainda que já se conheçam alguns programas e ações voltadas para a equidade de gênero nos diversos setores da vida social, inclusive no âmbito da educação com políticas educacionais brasileiras que especificam esta abordagem (Balieiro, 2017), voltadas às interfaces entre gênero e a divisão sexual no trabalho (Araujo, 2017), os avanços no campo das políticas públicas concernentes à criação de projetos e leis que efetivamente garantam a participação da mulher nos mais diversos setores da sociedade (Aguião, 2017) só serão equalizados quando as discussões ultrapassarem os muros locais $e$ assumirem uma perspectiva global. Isto decorre do fato de que, em um cenário absolutamente pluralizado, as discussões de gênero ultrapassam as 
questões relativas aos estudos das feminilidades e masculinidades, perpassando o universo das identidades plurais de gênero (Butler, 2014).

No meio acadêmico, as pesquisas científicas têm abordado a temática de gênero com enfoques variados. No entanto, quando esta é associada à modalidade esportiva Corfebol, a ênfase recai sobre os artigos científicos relacionados aos aspectos fisiológicos, biomecânicos, metabólicos, nutricionais (Kok; Klaassen; Backx, 2011; Bergen; Reilingh; Dijk, 2011; Der Does et alii, 2016), e aspectos psicológicos (Dhayal Parveen; Ashok, 2013). Contudo, no campo sociológico e educacional, ainda é tímida a produção do conhecimento que tem como foco principal as interfaces das questões de gênero $e$ do empoderamento da mulher em um esporte peculiar, com características mistas, tornando este um importante desafio para a presente pesquisa.

Ao longo dos anos, abordagens relacionadas ao empoderamento feminino foram discutidas nas mais variadas áreas do conhecimento, como na área da saúde (Santos et alii, 2018), da economia (Cornwall, 2018), da sociologia (McDonald, 2015) e sua prática pode ser observada nos mais variados espaços de ação social, dentre eles o familiar, o escolar e de minorias. Turner e Maschi (2015) relaciona o empoderamento a uma ferramenta transformadora no campo das relações sociais, promovendo a construção do pensamento crítico e o favorecimento de tomada de decisão, ação e conscientização. Para os autores, trata-se de um sentimento pessoal fortalecido, o qual independe de mudanças na estrutura social, pois a estrutura interna se encontra empoderada no momento em que se consegue enxergar os obstáculos como desafios e oportunidades de crescimento.

Hargreaves (2000) discorreu sobre o empoderamento da mulher no esporte e apontou em seu estudo que o rompimento, pelas mulheres, de padrões de desigualdade no âmbito das práticas corporais e esportivas, fortemente marcadas pela hegemonia masculina, as tornará mais seguras para vivenciar as práticas esportivas, assim como, para divulgar suas experiências 
positivas no esporte. Esse autor ainda ressalta elementos como a motivação, os significados da prática e o impacto desse envolvimento, como aspectos importantes na construção $e$ fortalecimento do eu interior e da identidade.

Diante do exposto, este estudo centrou-se na perspectiva de contribuir com as reflexões sobre a utilização de esportes com características mistas, em específico o Corfebol, o qual desde a sua origem traz a inclusão feminina para o contexto das vivências corporais esportivas, para ampliar a conscientização sobre os valores da igualdade de gênero no esporte. Para tanto, objetivouse investigar a produção de conhecimento científico referente às interfaces de gênero e empoderamento da mulher no Corfebol.

\section{Procedimentos metodológicos}

O presente estudo, de natureza qualitativa foi desenvolvido por meio de uma revisão descritiva da literatura, a qual procura fazer um aporte das pesquisas já realizadas sobre a temática proposta e promover a ampliação e a construção de releituras aprimoradas destes estudos (Gomes; Caminha, 2014). Esta revisão foi realizada em um período temporal compreendido entre o dia 1 de agosto de 2017 até o dia 31 de dezembro de 2017, obedecendo a um conjunto de critérios de inclusão e exclusão.

Como critérios de inclusão, ficaram estabelecidos: artigos abertos e na íntegra, disponíveis para download e leitura na plataforma. Artigos publicados em qualquer ano. Como critérios de exclusão: artigos não científicos, como leis, legislações e regras, matérias de jornal e revistas sem caráter científico. Artigos científicos que abordavam temáticas relacionadas aos aspectos fisiológicos e biomecânicos (lesões), ao metabolismo e à nutrição ligados ao Corfebol e artigos que versavam sobre gênero e esporte de maneira geral - se o Corfebol não era o foco principal.

As bases de dados consultadas para este estudo, disponíveis no Portal de Periódicos CAPES/MEC (Coordenação de Aperfeiçoamento de Pessoal de Nível Superior) do Ministério da Educação, são mostradas a seguir. Quanto as áreas do 
conhecimento, buscou-se nas Ciências da Saúde (Educação Física e Esportes), Humanas (Sociologia, Educação e Psicologia) e Multidisciplinar (Interdisciplinar) pelas bases EBSCO (Academic Search Premier - ASP, CINAHL, SocINDEX with Full Text, SPORTDiscus with Full Text, MEDLINE), Webofscience, ScienceDirect e Scopus. Utilizou-se também a ferramenta de busca Google Scholar, para fins de averiguar a existência de artigos não disponibilizados nas bases citadas. Para a realização da pesquisa, foram adotadas as seguintes palavras-chave como estratégia de busca: korfball OR corfebol AND gender AND power. Como resultado da combinação dos termos, chegou-se ao número geral de 579 artigos.

\section{Resultado e discussão}

Diante do total de 579 manuscritos, ao serem aplicados os critérios de inclusão foram excluídos 36 artigos, os quais se encontravam repetidos em mais de uma base de dados, bem como, 536 artigos que não atenderam aos critérios estabelecidos. Destes 536 manuscritos, 206 versavam sobre leis, legislações, regras, manuais de curso/treinamento, matérias de jornal e revistas de divulgação, porém, sem caráter científico. Outros 175 artigos abordavam as questões de gênero e esporte de maneira geral $e$ o Corfebol não era o foco principal dos estudos, sendo, apenas, citado como um esporte entre tantos outros jogados por equipes. Outros 130 artigos abordavam temáticas relacionadas aos aspectos fisiológicos e biomecânicos, como no caso de lesões, rompimentos de ligamentos, problemas ligados ao sistema muscular, ósseo e circulatório, como também relativos às questões de metabolismo/nutrição ligadas ao esporte; 25 artigos potencialmente apropriados para fazer parte da amostra se encontravam fechados, sem acesso livre para a leitura, resultando, assim, 7 artigos importantes selecionados nesta revisão descritiva da literatura.

Quanto aos critérios de análise dos artigos selecionados, foram levados em consideração os nomes dos autores, o ano de 
publicação, o delineamento metodológico, os objetivos, os principais resultados e conclusões. Diante da análise dos sete artigos encontrados, em relação à categoria 1- estratégias metodológicas dos manuscritos, estudos exploratórios de natureza qualitativa sobressaíram. Os instrumentos utilizados para a coleta de dados fazem relação às observações, questionários $e$ entrevistas, elementos estes que se encontram inseridos dentro dos delineamentos utilizados nos estudos, como as pesquisas documentais e etnográficas, as quais tiveram os dados analisados de maneira descritiva. Diante deste cenário, constatou-se que os manuscritos procuraram valorizar $e$ interpretar as realidades sociais investigadas, as ações humanas e as significações que os atores sociais conferem a elas.

A categoria 2- principais conteúdos abordados, almejou explorar os artigos selecionados, na tentativa de promover um debate acerca dos diferentes enfoques dados às temáticas do presente estudo. Os dados são apresentados no Quadro 1, a seguir.

Quadro 1 - Categoria de análise "Principais conteúdos abordados" - objetivos, principais resultados e conclusões.

\section{Autor/Ano \\ Objetivo \\ Principais Resultados \\ Conclusões}

Crum (1988)

Investigar se o corfebol
corrobora a afirmativa
da Federação
Internacional de
Corfebol (IKF), a qual
afirma ser o esporte um
passaporte para a
coeducação

-Gestão esportiva

fortemente masculina -

mulher sub-representada

em cargos menores;

-Quanto ao status do

jogador em relação à

maior pontuação, os

dados para as

equipes mostraram igual

distribuição de posições

de status para ambos

os gêneros.

-As mulheres

tendem a rejeitar a ideia
-Os esportes coeducacionais, como o corfebol, podem auxiliar na minimização do processo de segregação sexual no esporte, a qual ainda prevalece nos esportes tradicionais.

-O sistema tático do corfebol favorece a divisão igual de funções entre os gêneros dentro do jogo. -A elevação do estatuto do desporto feminino e a humanização do esporte têm 


\begin{tabular}{|c|c|c|c|}
\hline & & $\begin{array}{l}\text { da superioridade } \\
\text { masculina no esporte } \\
\text { enquanto os } \\
\text { homens tendem a conco } \\
\text { rdar com a ideia. } \\
\text {-Quanto às atitudes, os } \\
\text { jogadores homens de } \\
\text { corfebol têm maior } \\
\text { respeito pelas mulheres } \\
\text { no esporte. }\end{array}$ & $\begin{array}{l}\text { mais chances em um esporte } \\
\text { coeducacional como corfebol, } \\
\text { do que em outros esportes } \\
\text { coletivos. }\end{array}$ \\
\hline $\begin{array}{l}\text { Summerfield; } \\
\text { White (1989) }\end{array}$ & $\begin{array}{l}\text { Averiguar a afirmativa } \\
\text { de que o corfebol } \\
\text { praticado na Grã- } \\
\text { Bretanha é um esporte } \\
\text { igualitário }\end{array}$ & $\begin{array}{l}\text {-A análise dos } \\
\text { documentos evidenciou } \\
\text { que os homens são } \\
\text { protagonistas, enquanto } \\
\text { as mulheres assumem } \\
\text { posição secundária. } \\
\text {-A produção cientifica } \\
\text { evidenciou que cerca de } \\
55 \% \text { dos artigos e } 65 \% \\
\text { dos editores convidados } \\
\text { foram escritos por } \\
\text { homens, comparado } \\
\text { com } 18 \% \text { e } 12 \% \text { pelas } \\
\text { mulheres. } \\
\text {-Os cargos de gestão } \\
\text { ainda são ocupados } \\
\text { pelo público masculino, } \\
2 \text { para } 1, \text { ficando as } \\
\text { mulheres sub- } \\
\text { representadas. } \\
\text {-Foi evidenciado, que } \\
\text { no Korfball da Grã- } \\
\text { Bretanha, todas as } \\
\text { equipes tinham homens } \\
\text { como capitães e } \\
\text { treinadores e que a } \\
\text { desigualdade de gênero } \\
\text { é fortemente presente } \\
\text { em vários segmentos do } \\
\text { jogo. }\end{array}$ & $\begin{array}{l}\text {-A desigualdade de gênero foi } \\
\text { percebida em todas as } \\
\text { linguagens e materiais } \\
\text { ilustrativos dos documentos } \\
\text { analisados, revelando que no } \\
\text { esporte, o papel masculino é } \\
\text { proeminente em relação à } \\
\text { mulher. } \\
\text {-Tanto os jogadores de } \\
\text { corfebol, quanto os técnicos e } \\
\text { treinadores, necessitam criar } \\
\text { políticas e estratégias que } \\
\text { assegurem a igualdade de } \\
\text { oportunidades entre os } \\
\text { gêneros. } \\
\text {-As relações de poder } \\
\text { patriarcal ainda sobressaem } \\
\text { quando se fala de jogos com } \\
\text { equipes mistas. A } \\
\text { superioridade masculina no } \\
\text { esporte ainda corrobora para } \\
\text { práticas de exclusão e } \\
\text { subordinação da mulher no } \\
\text { esporte. }\end{array}$ \\
\hline
\end{tabular}




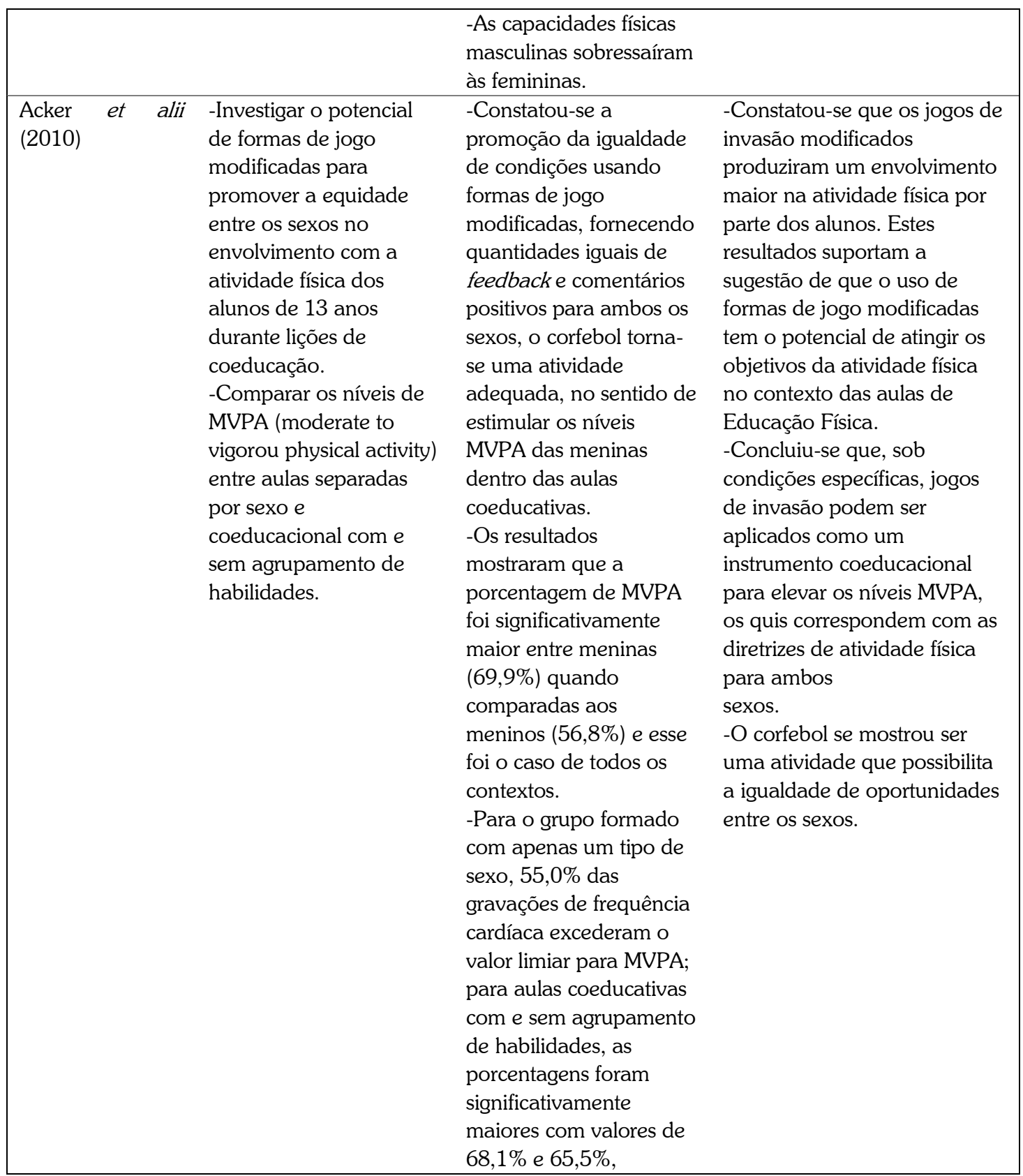




\begin{tabular}{|c|c|c|c|}
\hline & & $\begin{array}{l}\text { respectivamente. } \\
\text {-O nível mais baixo de } \\
\text { MVPA médios dos } \\
\text { meninos pode estar } \\
\text { relacionado aos aspectos } \\
\text { motivacionais. É } \\
\text { possível que os meninos } \\
\text { foram menos receptivos } \\
\text { quanto a trabalhar um } \\
\text { esporte, como o } \\
\text { corfebol, que prega a } \\
\text { igualdade de } \\
\text { oportunidades pois se } \\
\text { sentiram ameaçados } \\
\text { quanto a exercer o papel } \\
\text { de liderança numa } \\
\text { atividade neutra. }\end{array}$ & \\
\hline $\begin{array}{l}\text { Bottenburg; } \\
\text { Vermeulen } \\
\text { (2011) }\end{array}$ & $\begin{array}{l}\text { Investigar a razão de o } \\
\text { corfebol, mesmo sendo } \\
\text { semelhante ao basquete } \\
\text { em vários pontos, } \\
\text { manter-se como um } \\
\text { esporte local em seu país } \\
\text { de origem, enquanto o } \\
\text { basquete experimentou } \\
\text { um boom global. }\end{array}$ & $\begin{array}{l}\text {-O basquete se espalhou } \\
\text { pelo continente } \\
\text { americano e pelos países } \\
\text { da América do Sul antes } \\
\text { da primeira guerra } \\
\text { mundial e o corfebol se } \\
\text { limitou a Europa; } \\
\text {-Os professores } \\
\text { holandeses não } \\
\text { promoveram o corfebol } \\
\text { internacionalmente e, } \\
\text { até a segunda guerra } \\
\text { mundial, o corfebol não } \\
\text { havia saído do } \\
\text { continente europeu; } \\
\text {-As atitudes propagadas } \\
\text { pelo corfebol o tornaram } \\
\text { único, assim como as } \\
\text { premissas em relação às } \\
\text { questões de igualdade } \\
\text { entre os gêneros; } \\
\text {-Os processos ligados à } \\
\text { esportivização, } \\
\text { globalização e }\end{array}$ & $\begin{array}{l}\text {-Concluiu-se que o diferencial } \\
\text { para que o basquetebol } \\
\text { atingisse níveis globais em } \\
\text { relação ao corfebol, é em } \\
\text { suma, graças às diferenças } \\
\text { nos contextos sociais e } \\
\text { culturais. Os esportes e suas } \\
\text { regras são adaptados } \\
\text { conforme valores sociais } \\
\text { vigentes na época. } \\
\text {-Pela sua característica } \\
\text { coeducativa, diferenciando da } \\
\text { maioria dos esportes } \\
\text { praticados por equipes } \\
\text { divididas por gênero, o } \\
\text { corfebol foi projetado } \\
\text { intencionalmente por } \\
\text { professores para alunos do } \\
\text { sexo masculino e feminino } \\
\text { nas escolas e passou a ser } \\
\text { visto como uma opção } \\
\text { esportiva diferente aos } \\
\text { esportes tradicionais } \\
\text { comercializados, como o }\end{array}$ \\
\hline
\end{tabular}




\begin{tabular}{|c|c|c|c|}
\hline & & $\begin{array}{l}\text { comercialização ainda } \\
\text { não corroeram as } \\
\text { estruturas e alicerces } \\
\text { sobre os quais o corfebol } \\
\text { ainda se sustenta; }\end{array}$ & $\begin{array}{l}\text { futebol e esportes menos } \\
\text { tradicionais no âmbito das } \\
\text { escolas, como tênis e hóquei } \\
\text { em campo. } \\
\text {-Houve a mercantilização dos } \\
\text { esportes altamente rentáveis, } \\
\text { como futebol, basquete entre } \\
\text { outros e o corfebol se prendeu } \\
\text { às tradições. }\end{array}$ \\
\hline $\begin{array}{l}\text { Gubby; Wellard } \\
\text { (2015) }\end{array}$ & $\begin{array}{l}\text { Descobrir as maneiras } \\
\text { em que as questões de } \\
\text { gênero foram } \\
\text { negociadas, contestadas } \\
\text { ou recriadas numa } \\
\text { equipe de corfebol } \\
\text { júnior e examinar em } \\
\text { que medida o corfebol } \\
\text { contribui para a } \\
\text { promoção da igualdade } \\
\text { de oportunidade entre } \\
\text { os gêneros. }\end{array}$ & $\begin{array}{l}\text {-Os dados foram } \\
\text { analisados sob } \\
\text { categorias: } \\
\text { interpretações de gênero } \\
\text { na quadra de corfebol; } \\
\text { uniformes dos } \\
\text { jogadores; questões } \\
\text { relacionadas à } \\
\text { masculinidade e } \\
\text { feminilidade e as } \\
\text { diferenças entre } \\
\text { meninos e meninas. } \\
\text {-Quanto ao formato de } \\
\text { jogo, o corfebol parecia } \\
\text { incentivar a igualdade } \\
\text { entre os sexos na } \\
\text { quadra. } \\
\text {-Alguns jogadores } \\
\text { acreditavam que os } \\
\text { meninos tinham } \\
\text { vantagens físicas no } \\
\text { esporte e que, } \\
\text { provavelmente, eram } \\
\text { mais fisicamente } \\
\text { assertivos ou agressivos } \\
\text { que as meninas na } \\
\text { mesma situação. } \\
\text {-Alguns jogadores } \\
\text { relataram que alguns } \\
\text { esportes desenvolvidos } \\
\text { nas aulas de Educação } \\
\text { Física são de }\end{array}$ & $\begin{array}{l}\text {-Percebeu-se que a } \\
\text { compreensão das questões } \\
\text { relacionadas a gênero estava } \\
\text { baseada em normas sociais } \\
\text { tradicionais; quanto ao } \\
\text { vestuário, os shorts-saia } \\
\text { usados pelas meninas } \\
\text { indicavam papéis sociais de } \\
\text { gênero e os termos } \\
\text { masculinidade e feminilidade } \\
\text { e suas relações com atributos } \\
\text { ou ações corporais foram } \\
\text { identificados no estudo. } \\
\text {-Quanto às diferenças, estas } \\
\text { foram remetidas às } \\
\text { características físicas e às } \\
\text { características entre os } \\
\text { esportes tradicionais. } \\
\text {-Concebido para encorajar } \\
\text { meninos e meninas a } \\
\text { participar em condições } \\
\text { equitativas, refutar a violência } \\
\text { e formar um jogo igualitário, o } \\
\text { corfebol se mostrou um } \\
\text { esporte ímpar. }\end{array}$ \\
\hline
\end{tabular}




\begin{tabular}{|c|c|c|c|}
\hline & & $\begin{array}{l}\text { predomínio masculino e } \\
\text { o corfebol parece ser } \\
\text { uma resposta potencial } \\
\text { para o problema. }\end{array}$ & \\
\hline $\begin{array}{l}\text { Antônio Pereira } \\
\text { et alii (2016a) }\end{array}$ & $\begin{array}{l}\text { Examinar as } \\
\text { experiências de oito } \\
\text { atletas de elite } \\
\text { portugueses, valorizando } \\
\text { as experiências } \\
\text { subjetivas e qualitativas } \\
\text { dos próprios esportistas } \\
\text { e os principais agentes } \\
\text { socializadores que } \\
\text { desempenham um papel } \\
\text { fundamental em seu } \\
\text { sucesso esportivo, nos } \\
\text { pontos altos e baixos em } \\
\text { suas jornadas para o } \\
\text { sucesso na carreira. }\end{array}$ & $\begin{array}{l}\text {-Categorias elencadas } \\
\text { pelo estudo - agentes de } \\
\text { socialização primária; os } \\
\text { pais, os professores de } \\
\text { Educação Física e } \\
\text { treinadores, amigos. } \\
\text {-Quanto aos pontos } \\
\text { fortes do esporte, estes } \\
\text { são caracterizados pelas } \\
\text { vitórias, no entanto, } \\
\text { funcionam em curto } \\
\text { prazo, já o sacrifício e a } \\
\text { dedicação são } \\
\text { elementos que, em } \\
\text { longo prazo, promovem } \\
\text { o sucesso na carreira } \\
\text { esportiva. } \\
\text {-Quanto aos pontos } \\
\text { fracos, não obter } \\
\text { resultados (incluindo } \\
\text { derrotas esportivas) e } \\
\text { experiências de lesões. }\end{array}$ & $\begin{array}{l}\text {-Os picos e as vagas } \\
\text { percebidas das carreiras dos } \\
\text { ex-atletas de elite giravam em } \\
\text { torno do sucesso competitivo, } \\
\text { derrota / perda e falha em } \\
\text { alcançar os resultados } \\
\text { previstos e o início e efeitos da } \\
\text { lesão. } \\
\text {-A valorização dos relatos de } \\
\text { ex-atletas e suas experiências } \\
\text { de vida, relacionadas ao } \\
\text { esporte, servem de pano de } \\
\text { fundo para as novas gerações } \\
\text { de atletas, as quais podem se } \\
\text { orientar e aprender sobre suas } \\
\text { capacidades, via aspectos } \\
\text { subjetivos evidenciados nos } \\
\text { relatos. } \\
\text {-Importância de mais } \\
\text { pesquisas qualitativas, sob o } \\
\text { viés da sociologia do esporte, } \\
\text { haja vista que, a grande } \\
\text { maioria dos trabalhos, valoriza } \\
\text { aspectos biomecânicos e } \\
\text { fisiológicos. }\end{array}$ \\
\hline Paixão (2017) & $\begin{array}{l}\text { Relatar a vivência de } \\
\text { uma proposta de } \\
\text { práticas pedagógicas por } \\
\text { acadêmicos do curso de } \\
\text { licenciatura em } \\
\text { Educação Física, } \\
\text { vinculados ao Programa } \\
\text { Institucional de Bolsa de } \\
\text { Iniciação à Docência da } \\
\text { Universidade Federal de } \\
\text { Viçosa, numa escola da }\end{array}$ & $\begin{array}{l}\text {-A prática } \\
\text { intervencionista resultou } \\
\text { em pontos positivos no } \\
\text { que tange à inserção de } \\
\text { uma nova modalidade } \\
\text { no contexto escolar; } \\
\text {-Destacaram a } \\
\text { importância do } \\
\text { planejamento coletivo e } \\
\text { a preparação de ações } \\
\text { pedagógicas, evitando }\end{array}$ & $\begin{array}{l}\text {-O corfebol promoveu } \\
\text { inúmeros desafios, como } \\
\text { também proporcionou } \\
\text { experiências e aprendizagens } \\
\text { acerca do referido esporte, } \\
\text { pouco difundido no Brasil e, } \\
\text { por conseguinte, nas aulas de } \\
\text { Educação Física. } \\
\text { - No tocante às questões de } \\
\text { gênero, percebeu-se que, nas } \\
\text { discussões nas reuniões com o }\end{array}$ \\
\hline
\end{tabular}




\begin{tabular}{|lll|}
\hline rede pública estadual na & situações imprevisíveis; & grupo, sobre situações \\
cidade de Viçosa, MG. & -As questões de gênero & ocorridas durante a \\
trabalhadas com os & intervenção, a superioridade \\
& acadêmicos em relação & masculina não se concretizou, \\
ao corfebol instigaram & devido ao esporte promover a \\
reflexões e situações que & igualdade de oportunidades \\
& ocorriam durante os & entre os gêneros, assim como, \\
& momentos de & pelas meninas, que se viram \\
intervenção na escola. & interagindo com os meninos \\
& & durante a experiência.
\end{tabular}

Fonte: Elaborado pelas autoras (2019).

Nessa categoria sobre os principais conteúdos abordados, no primeiro item, objetivos, quatro manuscritos (Crum, 1988; Summerfield; White, 1989; Acker et alii, 2010; Gubby; Wellard, 2016) procuraram averiguar sobre o Corfebol e suas possíveis contribuições à igualdade de gênero e nos processos de coeducação. Os autores teceram reflexões importantes sobre o Corfebol e promoveram indagações sobre este ser um esporte que contribui para a igualdade de oportunidades entre os gêneros.

Ao levarem em consideração as aulas de Educação Física quando vivenciadas em sistema de coeducação, a tendência, segundo Mattos (2014), é diminuir ou quebrar o status quo, o qual, geralmente promove a desigualdade nas relações de gênero no contexto esportivo. Gonçalves (2017) evidenciou pontos positivos em relação às aulas coeducativas de Educação Física, enfatizando que diante do convívio de ambos os sexos, em diferentes atividades esportivas, meninas e meninos terão oportunidades de desenvolver o respeito e a romper com estereótipos.

No entanto, Wood e Garn (2016) revelaram que diversos esportes tiveram suas regras modificadas, para que a participação feminina pudesse se concretizar. Comumente chamados de esportes "coed", tem-se o softbol, o futebol americano e o futebol de bandeiras, como atividades exemplo. Entretanto, o cenário que se mostra encoberto por essa bandeira "coed", em nada contribui para a igualdade e equalização entre os gêneros no esporte; ao contrário, corrobora para edificação de estereótipos, de acordo 
com os autores. A fragilidade da presença feminina é evidenciada nesses esportes, devido às regras modificadas e posições assumidas durante a prática, subalternas e inferiores.

Ainda neste contexto escolar, o estudo desenvolvido por Paixão (2017) procurou quebrar a hegemonia das modalidades tradicionais esportivas nas aulas de Educação Física escolar, promovendo a vivência do Corfebol. $\mathrm{O}$ autor acredita que os esportes mistos tendem a promover a desconstrução de valores $e$ crenças construídos socialmente acerca das qualidades físicas de homens e mulheres. Em conformidade, Dos Anjos (2016) enfatizou que as práticas esportivas não convencionais, no caso o Corfebol, ao serem vivenciadas nas aulas de Educação Física, tendem a promover a igualdade de oportunidades entre os gêneros. $\mathrm{O}$ autor relatou ainda que o Corfebol, diante de seus princípios, promove a inclusão dos alunos que não dispõem de grandes habilidades em esportes coletivos.

Outro manuscrito analisado, de caráter teórico, se propôs a investigar os motivos de ambos esportes coletivos, Basquete $e$ Corfebol, com suas semelhanças em vários pontos, terem seguido trajetórias diferenciadas, tanto geograficamente quanto socialmente, ao longo dos tempos (Bottenburg; Vermeulen, 2011). Atento às transformações sociais, os esportes tendem a se reinventar ou promover modificações em suas estruturas, de forma a acompanhar o ritmo das mudanças da sociedade moderna (Pereira et alii, 2016b). Neste sentido, os autores da pesquisa analisada buscaram evidências na literatura para explicar esse fenômeno ocorrido com ambos os esportes.

Dentre os objetivos analisados, o estudo de Pereira et alii (2016a) manteve o foco nas experiências subjetivas e qualitativas de oito atletas de alto nível e quais os principais agentes socializadores que desempenharam um papel fundamental na carreira profissional. Sob o viés das Ciências Sociais e não da performance em si, estes puderam discorrer sobre os principais elementos relacionados ao Corfebol de alto rendimento. Rubio (1999) evidenciou em seu estudo, que a área da Psicologia do Esporte, responsável pelas pesquisas acerca do treinamento $e$ 
otimização da performance de atletas e equipes fornecendo assistência psicológica aos profissionais, ao se unir às outras grandes áreas do conhecimento, como Sociologia, Antropologia, Filosofia entre outras, compõem a conhecida Ciências do Esporte, a qual valoriza os aspectos sociais, educacionais e clínicos do contexto esportivo.

Pode-se perceber que os principais objetivos analisados fizeram relação às seguintes temáticas: Corfebol e gênero no âmbito dos esportes de alto rendimento, no contexto escolar, nas aulas de Educação Física e um estudo teórico comparativo de duas modalidades esportivas, o Corfebol e o basquete, cuja discussão perpassa o viés da globalização esportiva.

Quanto aos principais resultados, três manuscritos versaram sobre as diferenças de capacidade física entre homens e mulheres. No estudo de Crum (1988), os atletas masculinos corroboram a ideia da existência dessa superioridade, enquanto que as atletas mulheres discordam. No manuscrito analisado de Summerfield e White (1989), as capacidades físicas puderam ser evidenciadas via o processo de observação das equipes. Estas ficaram evidentes nos fundamentos observados (passe, arremesso, penalidades, saída de bola). O estudo de Gubby e Wellard (2016) constatou que, na visão dos jogadores, os meninos tinham mais vantagens físicas em relação às meninas.

As desigualdades entre os gêneros no contexto esportivo se dão por dois motivos, segundo Capranica et alii (2013): 1) as diferenças biológicas e estruturais de homens e mulheres, as quais definitivamente corroboram para as diferentes performances e 2) a falta de políticas públicas que favoreçam a entrada da mulher ao meio esportivo. Outros fatores contribuem para essas discrepâncias entre os gêneros, como os de ordem social $e$ política, carência de incentivos, de patrocínios e de oportunidades, que influenciam diretamente na participação feminina em uma variedade menor de esportes, ou em cargos esportivos e de gestão.

Os esportes tradicionais coletivos classificados como de invasão, a exemplo, o handebol, o basquete, o futebol, os quais 
ainda possuem equipes femininas e masculinas separadamente, tendem a acentuar as diferenças entre os gêneros. Essa separação pode vir a contribuir para a reprodução das desigualdades $e$ reforçar estereótipos masculinos (Hargreaves; Anderson, 2014).

A integração de homens e mulheres em equipes esportivas representa um avanço no que tange à desconstrução social do gênero, segundo Channon et alii (2015). Os autores apontam que as experiências vivenciadas, quer sejam no contexto dos treinamentos, ou em situações de jogo, favorecem mudanças de atitude que repercutem em outros setores, como o social, o pessoal e, até mesmo, no âmbito do trabalho, relacionado ao reconhecimento das diferentes capacidades $e$ habilidades femininas. O Corfebol, desde sua criação, se mostra como um espaço no qual homens e mulheres jogam em igualdade de oportunidades e condições. As diferenças relacionadas aos atributos físicos e as habilidades são descontruídas, as relações de gênero podem ser trabalhadas, devido ao fato de o esporte contribuir para a valorização $e$ a incorporação de conceitos relativos ao respeito, à cooperação $e$ a não violência entre os sexos (Crum, 2014).

Dois estudos relataram sobre a gestão esportiva marcada fortemente pela participação masculina, cabendo à figura feminina a sub-representação em cargos de menor prestígio (Crum, 1988; Summerfield; White, 1989). Atualmente, esses dados ainda vigoram (Zanatta et alii, 2018). A baixa participação feminina em cargos de liderança e chefia são verificados em vários setores do esporte, em federações e confederações e também, quando se focalizam as organizações olímpicas, como o Comitê Olímpico Internacional (COI).

Dois manuscritos apontaram resultados relacionados aos aspectos da igualdade de gênero no Corfebol. O estudo de Crum (1988) revelou a existência de um equilíbrio em termos de pontuação nos jogos, mostrando uma distribuição igual entre as posições assumidas no jogo. Acker et alii (2010) verificou que o Corfebol se mostrou como um espaço que permite promover $e$ possibilitar experiências únicas e oportunidades iguais entre os 
meninos e meninas. Esses dados foram corroborados no estudo de Gubby e Wellard (2016), no qual os autores constataram elementos interessantes em relação às discussões de gênero no âmbito do Corfebol, a divisão e as regras do jogo em quadra contribuíam para a igualdade de gênero, a dominância masculina não foi identificada quanto à natureza vocal do jogo, o que caracteriza que as meninas sobressaíram aos meninos em termos de comando de jogo dentro da quadra.

No contexto das aulas de Educação Física escolar, o estudo de Paixão (2017) gerou resultados positivos em relação à inserção de um esporte não convencional nas aulas de Educação Física, no sentido de promover experiências únicas e catalisadoras de mudanças de atitude frente à desigualdade entre homens $e$ mulheres no âmbito das práticas corporais. Diante da vivência do Corfebol realizadas por alunos de uma escola da rede pública, os futuros professores de Educação Física puderam enxergar e refletir sobre questões de gênero no contexto escolar, assim como, se apropriar dos conteúdos disseminados por esse esporte, para fins de criação de planos de atividades condizentes com as mudanças de valores na sociedade atual.

Já o manuscrito de Acker et alii (2010) revelou dados a respeito dos níveis de atividades físicas de intensidade moderada a vigorosa (MVPA), por meio da vivência do Corfebol entre meninos e meninas nas aulas de Educação Física, os quais foram analisadas sob dois vieses: aulas coeducativas e separadas por gênero. Os resultados mostraram que o nível de atividade física foi significativamente maior entre meninas $(69,9 \%)$ quando comparadas aos meninos $(56,8 \%)$ em ambos os casos - turma em sistema coeducacional e turma separada por gênero. $\mathrm{O}$ nível mais baixo de MVPA médio dos meninos pode estar relacionado aos aspectos motivacionais. Segundo os autores, é possível que os meninos tivessem sido menos receptivos quanto a trabalhar com o Corfebol, os mesmos sentiram-se ameaçados quanto a exercer o papel de liderança numa atividade neutra. Carvalho et alii (2016) analisou os níveis de MVPA em adolescentes, de ambos os gêneros no contexto da prática esportiva nas aulas de Educação Física 
escolar e sinalizou que as meninas são mais ativas fisicamente que os meninos.

O estudo de Pereira et alii (2016a) na área da Psicologia do Esporte gerou resultados importantes. Os responsáveis pelo sucesso esportivo dos atletas, ou mais precisamente, os agentes de socialização primária, são a família (pais em particular), os professores de Educação Física (também atuam como treinadores em alguns casos) e os amigos. Esses resultados também foram encontrados por Santos e Duarte (2018), acerca das estruturas sociais como a família, principalmente os pais e a escola, as quais são responsáveis pela iniciação e consolidação de futuros atletas. Os pontos fortes, caracterizados pelas vitórias, e os fracos, não obtenção de resultados e derrotas no esporte, foram citados no estudo.

A pesquisa realizada por Bottenburg e Vermeulen (2011) evidenciou, com base nos três princípios relacionados à teoria da popularização diferencial dos esportes, que a evolução de um determinado esporte é um processo estruturado que se desenvolve em relação à mudança social. As práticas esportivas (Basquete e o Corfebol) promovem diferentes interpretações e estão sujeitas a se diferenciarem geograficamente, socialmente e ao longo do tempo. A construção do significado é um processo contínuo, influenciado pela mudança das relações sociais entre países e classes sociais, entre homens e mulheres, jovens e idosos, pessoas de diferentes regiões e grupos étnicos.

A mercantilização do Basquete se deu segundo Bottenburg (2016), pelo fato de o Basquete ter modernizado suas regras, expandido sua prática de forma rápida por todos os continentes e alcançado incentivos financeiros. O Corfebol, no entanto, manteve-se preso às suas regras e aos seus princípios, esporte tradicional, provinciano, que valorizava a participação da mulher em equipes mistas $e$, devido a esses fatores, não promoveu a disseminação deste, de forma global.

Miranda Filho e Santos (2014), em seu estudo sobre a tríade mídia, tecnologia e mercantilização esportiva, fornecem dados na tentativa de compreender esses processos ligados à expansão de 
determinados esportes. $\mathrm{O}$ fato de algumas modalidades esportivas adquirirem status diferenciado de outras, possui estreita relação com essa tríade evidenciada pelos autores. Os esportes de maneira geral possuem estreitas relações com o universo midiático, interferindo de maneira ativa na visão de como são passados para a sociedade. A espetacularização do esporte, segundo os autores, promove o crescimento e o conhecimento sobre determinada prática esportiva, tornando-a comerciável e enfatizando-a como produto de consumo.

No entanto, algumas ações têm sido feitas atualmente no sentido de divulgar todos os eventos esportivos de Corfebol: a Federação Internacional de Corfebol (International Korfball Federation, 2018) fechou um acordo com o The Olympic Chanel, em junho de 2018, órgão que atuará em parceria com a International Korfball Federation (IKF). Esta plataforma transmite conteúdos esportivos e informações variadas sobre os diferentes eventos esportivos, via canais de TV e outras mídias. Outros meios de comunicação também são destacados no estudo de Nurminen (2017), em relação à divulgação de determinados esportes. A

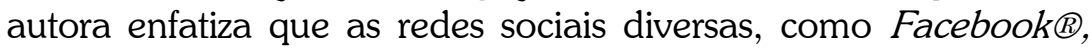
Instagram (B, entre outras, são ferramentas importantes na divulgação e propagação de conteúdos, no caso específico da sua tese, o Floorball no World Games, evento que antecede os Jogos Olímpicos. O Corfebol marca presença neste evento, considerado trampolim para as Olimpíadas, pois ganha visibilidade e se faz presente globalmente.

Quanto às Conclusões, pode-se constatar que a maior parte dos manuscritos analisados partilhou do fato de o Corfebol ser um esporte que auxilia na promoção da igualdade de oportunidades entre os gêneros, na minimização de atitudes preconceituosas em relação à participação da mulher em atividades esportivas. Dentre os manuscritos que creditam ao Corfebol essas premissas, tem-se o estudo de Crum (1988), o qual enfatizou ser este um meio interessante de juntar meninos e meninas na mesma equipe, favorecendo mudanças atitudinais em relação à segregação da mulher no âmbito das práticas esportivas. Para o autor, as regras, 
o sistema tático e as premissas expostos pelo Corfebol favorecem a divisão igualitária de funções dentro do jogo. Os esportes coeducacionais tendem a valorizar a participação feminina no esporte, além de ações e atitudes respeitosas em relação ao ser humano.

O estudo de Acker et alii (2010) concluiu ser este um esporte que promove a igualdade de oportunidades entre os gêneros $e$ enfatizou que jogos de invasão, como o Corfebol, se mostraram um espaço adequado para o incentivo à prática de atividade física dentro das aulas de Educação Física, assim como para estimular a participação das meninas neste contexto. Os autores reforçaram que o fato de incitar de maneira equilibrada a igualdade de condiçóes, feedbacks e comentários positivos para ambos os sexos em jogos de invasão, pode auxiliar na promoção da equidade entre os sexos, como também, estimular os níveis de MVPA das meninas no contexto das aulas coeducativas. Em estudos recentes com jogadoras de Corfebol, Sanjay (2017) identificou que o esporte promove uma série de elementos contribuintes para o desenvolvimento integral do ser humano, perpassando os aspectos psicológicos, sociológicos e biológicos. O Corfebol, segundo o autor, além promover o desenvolvimento de estratégias de jogo, atua diretamente na promoção de uma vida mais ativa propiciando um nível intenso de atividade física.

O estudo de Paixão (2017), no tocante às questões de gênero, enfatizou que nas aulas de Educação Física, o Corfebol promoveu a participação de meninos e meninas em igualdade de condições e que a superioridade masculina não se concretizou, o que acontece, segundo o autor, nos esportes tradicionais vivenciados nas aulas. Houve um aprendizado, por parte dos alunos de curso de graduação em licenciatura em Educação Física, sobre a temática de gênero no âmbito das práticas corporais. Barros, Oliveira e Rosário (2018) propõem em seu estudo a inserção de esportes diferenciados dos tradicionais ofertados no âmbito escolar, ressaltando a importância de se ministrar práticas corporais esportivas vivenciadas em outras culturas, em outros países, como o Corfebol, o rugby, o 
badminton, baseball, entre outras, contribuindo para a formação do aluno.

Gubby e Welard (2016) concluíram, em sua pesquisa, que o Corfebol foi criado no sentido de incentivar a inclusão de meninos e meninas em igualdade de condições, como também, rejeitar qualquer tipo de violência, verbal ou física nas práticas esportivas. No entanto, o entendimento sobre o universo das questões de gênero para os atletas de seu estudo estava baseado em normas $e$ padrões sociais tradicionais, os quais puderam ser constatados nas atitudes destes dentro e fora das quadras. Os autores sinalizaram alguns pontos que contradizem essa premissa de neutralidade de gênero. Um exemplo, pode ser referente aos uniformes das atletas de Corfebol, uma vez que o shorts-saia, na visão das atletas, confere símbolos indicativos de papeis de gênero tradicionais. Os termos feminilidade/masculinidade $e$ suas relações com os atributos ou ações corporais foram identificados nas falas dos atletas.

Sailors (2016) enfatizou que os esportes praticados sob a forma mista ou sob a bandeira "coed" ainda reforçam a segregação $e$ a desigualdade entre os gêneros no âmbito esportivo. Para vivenciar essas modalidades, são criadas regras para equalizar as condições entre os atletas no entanto, estas acabam por reafirmar a superioridade masculina e reforçar estereótipos, abrindo espaço para a misoginia, contribuindo com as manifestações de discriminação sexual, hostilidade $e$ androcentrismo. $\mathrm{O}$ autor possui uma visão diferenciada da maioria dos pesquisadores que acreditam nos valores presentes nesses esportes coeducativos (Messner, 2002; McDowell; Schaffner, 2011).

Um estudo se contrapôs ao fato de o Corfebol ser considerado uma prática esportiva que fomenta a igualdade entre os gêneros. Segundo o estudo britânico de Summerfield e White (1989), o Corfebol é um esporte diferenciado desde sua origem, pois promove a experiência esportiva entre os gêneros numa mesma equipe, no entanto, os valores emoldurados na sociedade em relação às estruturas de gênero reaparecem no espaço de 
quadra. Os autores concluíram ser este um esporte ainda fortemente marcado pelo patriarcalismo e pelo poder masculino em termos de capacidades físicas e habilidades motoras. A desigualdade de gênero se mostrou evidente durante a análise de diferentes documentos, observações de equipes e constataram que a figura masculina é proeminente em relação à da mulher. $\mathrm{O}$ manuscrito dos autores ainda apresentou um ceticismo em relação ao empoderamento da mulher por meio do Corfebol, assim como, de maneira geral, nos outros esportes mistos. A superioridade masculina reflete a natureza humana em si e esta sobressai à feminina, segundo esses autores.

No entanto, Paul, Steinlage e Blank (2015) constataram que, mediante o esporte praticado pelas mulheres, o empoderamento feminino pode ser entendido de forma diferenciada, haja vista que, no âmbito das práticas esportivas, este ainda está atrelado a valores morais e sociais culturalmente estabelecidos. Os autores evidenciaram que as mulheres praticantes de patins sobre rodas, de artes marciais e de rugby, assimilaram elementos relacionados ao empoderamento feminino, no sentido de que estas perceberam mudanças positivas em sua imagem corporal, como a aquisição de um corpo forte e saudável. A descoberta do poder, o qual ressignifica atitudes e comportamentos e promove o crescimento da confiança $e$ autoestima, repercutiu na vida pessoal $e$ profissional dessas atletas.

\section{Considerações finais}

O presente estudo procurou investigar a produção de conhecimento científico referente às interfaces das questões de gênero e empoderamento da mulher no contexto do Corfebol. Constatou-se, com a busca da produção científica sobre as temáticas, que nenhum artigo abordava todos os assuntos simultaneamente. As questões relativas à igualdade de gênero foram evidenciadas nos esportes de alto rendimento, assim como, no âmbito das aulas de Educação Física, no entanto, elementos 
relativos ao empoderamento feminino não foram encontrados na literatura analisada pelo presente estudo.

No contexto desta revisão, os achados versavam sobre o Corfebol e o fato do esporte atuar de maneira positiva, na promoção da igualdade de oportunidades entre os gêneros no contexto esportivo. Esta premissa se mostra atual no sentido das discussões sobre a participação e o empoderamento da mulher, por meio do esporte (Lim; Dixon, 2018). É fato que as práticas esportivas, sejam elas praticadas de maneira individual ou coletivamente, objetivando o alto rendimento ou não, inseridas ou não no ambiente educacional, são as mais diversas e atuam como catalisadoras de mudanças ao proporcionar ganhos positivos no que tange aos aspectos psicológicos, biológicos e sociais (Balagué et alii, 2016).

A fundação Canterbury Korfball constatou que o empoderamento no Corfebol é possível, e este se encontra em diferentes níveis, podendo ser obtido na aquisição de competências e habilidades físicas, no que tange ao ganho de autonomia e autoconfiança (Korfball Canterbury, 2018). O trabalho em equipe, assim como a cooperação, elementos fortemente presentes nas partidas de Corfebol, fomentam um diálogo constante entre os atletas. $\mathrm{O}$ empoderamento também pode ser ratificado por meio da igualdade de oportunidades entre os gêneros, haja vista a existência de regras de alternância de funções na partida, a exemplo do ataque e da defesa.

Não foi levado em consideração durante a ocasião da busca nas bases de dados, determinado período no tempo, demostrando com isso que as datas não importavam e sim, o acesso aos manuscritos e seus conteúdos. Três décadas separaram o primeiro manuscrito analisado, de Crum (1988) do estudo desenvolvido por Paixão (2017). Neste interim, pode-se constatar uma interessante evolução dos elementos que permeiam as discussões de gênero no âmbito das práticas esportivas. No entanto, poucos estudos têm direcionado seu foco para o Corfebol. De acordo com Gubby (2016), existe uma lacuna relacionada às pesquisas acadêmicas 
contemporâneas, cujo foco central seja as discussões sobre a igualdade de gênero no Corfebol. A autora revelou em seu estudo que as produções científicas que versaram sobre essas temáticas são datadas de 20 anos atrás, revelando, com isso, a importância do presente estudo.

Com relação aos aspectos metodológicos da pesquisa, constatou-se que os estudos exploratórios, de natureza qualitativa predominaram. Concernente aos instrumentos empregados nas coletas de dados, percebeu-se a utilização de questionários e entrevistas, assim como o uso da técnica de observação. Estes elementos se encontram inseridos dentro dos delineamentos utilizados nos estudos, como as pesquisas documentais $e$ etnográficas, os quais tiveram os dados analisados de maneira descritiva. Diante deste quadro, constatou-se que os manuscritos procuraram valorizar $e$ interpretar as realidades sociais investigadas, as ações humanas e as significações que os atores sociais conferem a elas.

Algumas limitações estiveram presentes neste estudo. Quanto à amostra, o número de artigos capturados nas bases de dados foi bastante reduzido. Este fato pode estar atrelado aos critérios de inclusão/exclusão estabelecidos, uma vez que, na dependência de se encontrarem trabalhos científicos produzidos especificamente sobre as temáticas desta revisão, o retorno de pesquisas científicas foi limitado. Ao longo da busca nas bases de dados, alguns artigos estavam em idiomas diferentes do inglês, como em holandês, chinês, alemão, entre outros, decorrentes de países que possuem uma ligação forte com o Corfebol na atualidade.

As discussões apresentadas neste estudo apontam direções variadas $e$ fomentam um terreno fértil a ser explorado por diferentes áreas do conhecimento. A temática de gênero no âmbito das práticas corporais estimula diálogos pertinentes $e$ atuais a serem ainda construídos em diferentes espaços da sociedade, juntamente com as tecnologias, as quais facilitam o acesso à informação e à propagação de conteúdos que promovam a equidade de oportunidade entre os gêneros. Sugerem, também, 
novas pesquisas, com outros termos de busca e a utilização de outras bases de dados, contribuindo ainda mais para a compreensão desta relevante temática.

\section{Referências bibliográficas}

ACKER, Ragnar van, et alii. Sex equity and physical activity levels in coeducational physical education: exploring the potential of modified game forms. Physical Education and Sport Pedagogy (15), Abingdon, 2010, pp. 159-173.

AGUIÃO, Silvia. Quais políticas, quais sujeitos? Sentidos da promoção da igualdade de gênero e raça no Brasil (2003 - 2015). cadernos pagu (51), Campinas, 2017, pp. 1-54 [http://www.scielo.br/pdf/cpa/n51/1809-4449-cpa18094449201700510007.pdf - acesso em 07 ago 2018].

ARAUJO, Anna Bárbara. Gênero no mundo do trabalho. cadernos pagu (51), Campinas, 2017, pp. 1-13 [http://www.scielo.br/pdf/cpa/n51/1809-4449-cpa18094449201700510024.pdf - acesso em 07 ago 2018].

BALAGUÉ, Natàlia, et alii. Sport science integration: An evolutionary synthesis. European Journal of Sport Science (17), Champaign, 2016, pp.

[https://www.tandfonline.com/doi/full/10.1080/17461391.2016.11984 22?casa_token $=$ rnUncSPF9tEAAAAA\%3Ac8_6wzKzvFtzUCUT9fbpDl avfc2kpal_vXA5S3KelkdcjUSzctsRGE1xyPv2ZJJUcoER3sYzmFDLg1m 4 - acesso em 07 ago 2019].

BALIEIRO, Fernando de Figueiredo. A "guerra" contra o gênero: reações às últimas décadas de políticas de promoção da igualdade de gênero no Brasil. cadernos pagu (51), Campinas, 2017, pp. 1-09 [http://www.scielo.br/pdf/cpa/n51/1809-4449-cpa18094449201700510022.pdf - acesso em 07 ago 2018].

BARros, Glhevysson dos Santos; Oliveira, Paulo Sérgio Pimentel de Oliveira; Rosário, Victor Hugo Rodrigues. Educação física e esporte: contribuições ao esporte da escola. Semioses (12), Rio de Janeiro, 2018, pp. 56-65. 
Bergen, Christiaan J. A. van; REILINGH, Mikel; DIJK, Niek C. Tertiary osteochondral defect of the talus treated by a novel contoured metal implant. Knee Surgery, Sports Traumatology, Arthroscopy (19), New York, 2011 , pp.

999-1003 [https://www.researchgate.net/publication/50401425_Tertiary_osteoch ondral_defect_of_the talus_treated_by_a_novel_contoured_metal_im plant - acesso em 20 ago 2019].

KORFBALL Canterbury. Be involved in korfball. 2018. [http://www.korfballcanterbury.co.nz/be-involved.html - Acesso em 27 ago 2018].

BOTTENBURG, Maarten van. Além da difusão: o esporte e sua reconstrução em contextos transculturais. Recorde: Revista de História do Esporte (9), Rio de Janeiro, 2016, pp. 1-18.

BOTTENBURG, Maarten van; Vermeulen, Jeroen. Local korfball versus global basketball: A study of the relationship between sports' rulemaking and dissemination. Ethnologie Française (41), Paris, 2011, pp. 633-643.

BUTLER, Judith. Regulações de Gênero. cadernos pagu (42), Campinas, 2014, pp. 249-274.

CAPRANICA, Laura, et alii. The gender gap in sport performance: equity influences equality. International Journal of Sports and Physiology and Performance (8), Champaign, 2013, pp.99-103.

CARVAlHO, Francisco, et alii. Haverá diferenças dos níveis de Atividade Física entre os rapazes $e$ as raparigas adolescentes nos vários contextos de prática? Boletim Sociedade Portuguesa de Educação Física (40), Linda-a-Velha, 2016, pp. 91-99.

CORNWALL, Andrea. Beyond "Empowerment Lite": Women's Empowerment, Neoliberal Development and Global Justice. cadernos pagu (52), Campinas, 2018, pp. $1-30$ [http://www.scielo.br/scielo.php?script=sci_arttext\&pid=S0104$83332018000100202 \& \operatorname{lng}=$ pt\&nrm $=$ iso\&tlng=en - acesso em 07 ago 2018].

ChANNON, Alex, et alii. The promises and pitfalls of sex integration in sport and physical culture. Sport in Society (19), Abingdon, 2015, pp. 1111-1124. 
CRUM, Bart. A Critical Analysis of Korfball as a" Non-Sexist Sport". International Review for the Sociology of Sport (23), Thousand Oaks, 1988, pp. 233-241.

Crum, Bart. Conceitos de Corfebol. Holanda, KNKV, 2014.

DER DOES, Henrike Teunisje Dorothé van, et alii. Injury risk is increased by changes in perceived recovery of team sport players. Clinical journal of sport medicine (27), New York, 2016, pp. 46-51.

DHAYAL PARVEEN, Tejpal; ASHOK, Kumar. A comparative study on personality level of national and international Korfball players. International Journal of Behavioural Social and Movement Sciences (2), Bagla/Rahya Suchani, 2013, pp. 52-55.

Dos ANJOS, Fernando Coelho. Corfebol nas aulas de educação física: uma possibilidade de esporte coletivo. In: Anais do $V$ Congresso Estadual De Educação Física Escolar e II Congresso Nacional De Educação Física Escolar, Rio Claro: UNESP, 2016.

DOSSIER DE KorfBAL. Departament D`Educació Física IES Joan Coromines. 2018. [http://blocs.xtec.cat/castells/files/2008/03/dossierkorfbol.pdf - acesso em 15 dez 2018].

GOMES, Isabelle Sena; Caminha, Iraquitan Oliveira. Guia para estudos de revisão sistemática: uma opção metodológica para as ciências do movimento humano. Movimento (20), Porto Alegre, 2014, pp. 395411.

GONÇALVES, Eduarda dos Passos. Gênero nas aulas de educação física: investigando o comportamento dos estudantes. Trabalho de conclusão de curso em Educação Física, Universidade Federal de Santa Catarina, Florianópolis, 2017.

GUBBY, Laura. Embodied practices in korfball. In: WeLLARD, I. Researching Embodied Sport. Exploring Movement Cultures. Abingdon, Routledge, 2015, pp. 86-99.

GUBBY, Laura. Can sport provide a space for gender equality? A qualitative study of children who play korfball. Tese (Doutorado em Filosofia), Canterbury Christ Church University, 2016.

GUBBY, Laura; WELLARD, Ian. Sporting equality and gender neutrality in korfball. Sport in Society (19), Londres, 2016, pp. 1171-1185. 
HARGREAVES, Jennifer. Heroines of Sport. The Politics of Difference and Identity. New York, Routledge, 2000.

HARGREAVES, Jennifer; ANDERSON, Eric. Sport, gender and sexuality: surveying the field. In: HARGREAVES, J.; ANDERSON, E. Routledge handbook of sport, gender and sexuality. Abingdon, Routledge, 2014, pp. 03-18.

International Korfball Federation. Statutes 2011. 2011. [http://ikf.org/wpcontent/uploads/2015/10/IKF-Statutes-2011-final-revised-version.pdf acesso em 15 mai 2018].

International Korfball Federation. IKF joins Olympic Channel. 2018. [https://ikf.org/ikf-joins-olympic-channel/ - acesso em 18 jul 2018].

KOK, H.; KLAASSEN, R.; BACKX, F. Effort thrombosis: A case report on a professional korfball player. Sport en Geneeskunde (44), Utrecht, 2011, pp. 20-25 [https://www.researchgate.net/scientificcontributions/2089427120_R_Klaassen - acesso em 20 ago 2019].

LAPCHICK, Richard. Gender report card: 2016 international sports report card on women in leadership roles. Institute for Diversity and Ethics in Sport, University of Central Florida. 2016. [http://nebula.wsimg.com/0e5c5c3e23367795e9ec9e5ec49fc9b2?Acc essKeyId=DAC3A56D8FB782449D2A\&disposition $=0 \&$ alloworigin $=$ 1 - acesso em 20 jun 2018].

LIM, So Youn; DixON, Marlene A. A conceptual framework of sport participation and women's empowerment. Managing Sport and Leisure (1), Abingdon, 2018, pp. 1-15.

MATTOS, Michele Ziegler de. Aulas mistas na Educação Física: tensões e contradições. Dissertação de Mestrado, Educação Física, Universidade Federal de Pelotas, Pelotas, 2014.

MCDONALD, Mary G. Imagining neoliberal feminisms? Thinking critically about the US diplomacy campaign, 'Empowering Women and Girls Through Sports'. Sport in Society (18), Abingdon, 2015, pp. 902-922.

MCDOWELL, Jacqueline; SCHAFFNER, Spencer. Football, it's a man's game: Insult and gendered discourse in The Gender Bowl. Discourse \& Society (22), Thousand Oaks, 2011, pp. 547-564.

MESSNER, Michael A. Taking the field: Women, men and sports. Minnesota, University of Minnesota Press, 2002. 
MIRANDA FILHO, Vamberto Ferreira; SANTOS, Igor Sampaio Pinho. Mídia, mercadorização esportiva e o movimento de popularização do MMA. Pensar a Prática (17), Goiânia, 2014, pp. 865-877.

NURMINEN, Minna. Social media campaign for the International Floorball Federation in connection to The World Games. Trabalho de conclusão de curso (Graduação em Gestão do Esporte e Lazer), Haaga-Helia University of Applied Sciences, Helsínquia, 2017.

ONU-Mulheres. ONU Mulheres e parceiros impulsionam empoderamento de meninas por meio do esporte. 2019. [https://nacoesunidas.org/onu-mulheres-e-parceiros-impulsionamempoderamento-de-meninas-por-meio-do-esporte/ - acesso em 03 out 2019].

PAIXÃO, Jairo Antônio. Corfebol na escola: uma proposta extracurricular de práticas pedagógicas por acadêmicos do curso de licenciatura em educação física. Scientific Electronic Archives (10), Sinop, 2017, pp. 96-103.

PAUL, John; SteinLage, Carolyn; BLANK, Sharla. Sport and bodily empowerment: female athletes experiences with roller derby, mixed martial arts and rugby. Journal of Alternative Perspectives in the Social Sciences (6), Flórida, 2015, pp. 402-438.

PEREIRA, Antônio, et alii. Journeys of Portuguese athletes to sporting success: the peaks and troughs. Journal of Physical Education and Sport (2), Pitesti, 2016a, pp. 397-406.

PEREIRA, Bruna Opieco, et alii. O esporte e a Indústria Cultural: A espetacularização e mercantilização do esporte na sociedade líquidomoderna. The Journal of the Latin American Socio-cultural Studies of Sport (6), Curitiba, 2016b, pp. 1-10.

RuBIO, Katia. A psicologia do esporte: histórico e áreas de atuação e pesquisa. Psicologia: ciência e profissão (19), Brasília, 1999, pp. 6069.

SAILORS, Pam R. Off the beaten path: should women compete against men? Sport in society (19), Abingdon, 2016, pp. 1125-1137.

SANJAY. Relationship between emotional intelligence and performance of Korfball player of Haryana. International Journal of Physiology, Nutrition and Physical Education (2), Nova Delhi, 2017, pp. 107-110. 
SANTOS, Luís Lucas Oliveira; DuARTE, Suênia de Lima. O entrelaçar dos fios na formação de João Júnior: a contribuição da família na formação de um atleta. Revista Redfoco (5), Pau dos Ferros, 2018, pp. 1-10.

SANTOS, Etiele Ortiz, et alii. Avaliação de empoderamento: considerações teórico-metodológicas aplicadas ao campo da saúde. Revista da Escola de Enfermagem da USP (52), São Paulo, 2018, pp. 1-8, nov. 2018.

SCHUlENKORF, Nico; SHERRY, Emma; RowE, Katie. Sport for development: An integrated literature review. Journal of Sport Management (30), Champaign, 2016, pp. 22-39.

SINGH, Tina Lee; NAIDOO, Logan. D. Assessing gender inequality in South Africa: a case study of women in sports management. Journal of Research in Business, Economics and Management (8), Lausanne, 2017, pp. 1407-1428.

SuMmERFIELD, Karen; WHITE, Anita. Korfball: A model of egalitarianism? Sociology of Sport Journal (6), Champaign, 1989, pp. 144-151.

TURNER, Sandra G.; MASCHI, Tina M. Feminist and empowerment theory and social work practice. Journal of Social Work Practice (29), Londres, 2015, pp. 151-162.

WoOD, Zacharias C.; GARN, Alex C. Leveling the playing field? Perspectives and observations of coed intramural flag football modifications. Sociology of Sport Journal (33), Champaign, 2016, pp. 240-249.

ZANATTA, Thaís Camargo, et alii. O perfil do gestor esportivo brasileiro: revisão sistemática da literatura. Movimento (ESEFID/UFRGS) (24), Porto Alegre, 2018, pp. 291-304. 